\title{
Investigation on room temperature photoluminescence of pure and aluminum doped zinc oxide nanoparticles
}

\author{
N. SRINIVASAN ${ }^{1 *}$, J.C. KANNAN ${ }^{2}$ \\ ${ }^{1}$ Department of Physics, Kongu Engineering College, Perundurai, Tamilnadu - 638 052, India \\ ${ }^{2}$ Department of Physics, KSR Institute for Engineering and Technology, Tiruchengode, Namakkal, Tamilnadu - 637 215, India
}

Pure and aluminum doped zinc oxide nanoparticles were prepared by soft chemical method. The prepared nanoparticles were characterized by XRD, SEM-EDAX, UV-Vis, PL and FT-IR studies. XRD patterns revealed that the nanoparticles were crystallized in hexagonal wurtzite structure with an average particle size of $19 \mathrm{~nm}$ to $26 \mathrm{~nm}$. The surface morphology was explored using SEM micrographs. The incorporation of aluminum was confirmed by EDAX and FT-IR studies. The band gaps of the particles were found from $3.48 \mathrm{eV}$ to $3.53 \mathrm{eV}$ through UV-Vis spectral studies. The defect related mechanism was investigated using PL measurements. The chemical functional groups in FT-IR spectra proved the formation of pure and aluminum doped zinc oxide nanoparticles.

Keywords: zinc oxide nanoparticles; PL measurements; soft chemical method

(C) Wroclaw University of Technology.

\section{Introduction}

The unique properties of nanomaterials have motivated researchers to investigate their technical applications. Semiconductor nanomaterials are excellent multifunctional materials. Zinc oxide has a wide band gap of $3.3 \mathrm{eV}$ and large exciton binding energy of $60 \mathrm{meV}$ [1]. Zinc oxide nanoparticles have outstanding properties, such as high infrared reflectivity, electrochemical stability, superior transparency in visible region and good electronic properties [2]. Zinc oxide is a II - IV n-type multifunctional metal oxide semiconductor due to native oxygen doping. The electrical conductivity of zinc oxide nanoparticles can be enhanced by the addition of dopants [3]. Zinc oxide nanoparticle is commonly doped with elements, such as $\mathrm{Al}[4,5]$, $\mathrm{Sn}$ [6], Mn [7], Ni [8], Co [9] and Cu [10]. Zinc oxide nanomaterials are used in such applications as solar cells [11], LPG sensors [12], and antibacterial effects [13]. Aluminum doped zinc oxide nanoparticles have a wide range of applications in many areas, such as fiber optic sensor [14], gas sensor [15].

*E-mail: sriphy01@gmail.com
Zinc oxide nanoparticles have been prepared by different methods, such as spray pyrolysis [16], hydrothermal [17], sol-gel [18], co-precipitation [19] and electrochemical method [20].

The present work aimed to investigate the room temperature photoluminescence properties of pure and aluminum doped zinc oxide nanoparticles synthesized by soft chemical method. The prepared nanoparticles were examined by $\mathrm{X}$-ray diffraction, scanning electron microscopy, energy dispersive $\mathrm{X}$-ray spectroscopy, UV-Vis spectrometry, photoluminescence measurements and Fourier transform infrared spectroscopy.

\section{Experimental}

\subsection{Synthesis}

Zinc nitrate hexahydrate $\left(\mathrm{Zn}\left(\mathrm{NO}_{3}\right)_{2} \cdot 6 \mathrm{H}_{2} \mathrm{O}\right)$, aluminum nitrate nonahydrate $\left(\mathrm{Al}\left(\mathrm{NO}_{3}\right)_{3} \cdot 9 \mathrm{H}_{2} \mathrm{O}\right)$ and sodium hydroxide $(\mathrm{NaOH})$ obtained from Merck Chemicals were used without further purification in this method. Zinc nitrate hexahydrate and aluminum nitrate nonahydrate were used as host and dopant precursors. 


\subsubsection{Soft chemical method}

The precursor solution was allowed for 24 hours reaction time at room temperature. The resulting precipitate was purified with deionized water several times and it was dried in air for 3 hours for the preparation of nanoparticles. The growth temperatures were chosen as $80{ }^{\circ} \mathrm{C}$ and $120{ }^{\circ} \mathrm{C}$ for sample ' $\mathrm{a}$ ' and ' $\mathrm{b}$ ', respectively. The aluminum concentration was 1 at. $\%$ and 3 at. $\%$ for the samples 'c' and 'd', and the growth temperature was chosen as $120^{\circ} \mathrm{C}$.

\subsubsection{Reaction mechanism}

The nanoparticles were prepared using the following reaction mechanism.

$$
\begin{gathered}
\left(\mathrm{Zn}\left(\mathrm{NO}_{3}\right)_{2}\right)+2 \mathrm{NaOH} \rightarrow \\
\mathrm{Zn}(\mathrm{OH})_{2}(\mathrm{~s})+2 \mathrm{NaNO}_{3}(\mathrm{aq}) \\
\mathrm{Zn}(\mathrm{OH})_{2} \rightarrow \mathrm{Zn}^{2+}+2 \mathrm{OH}^{-} \\
\mathrm{Zn}^{2+}+2 \mathrm{OH}^{-} \rightarrow \mathrm{ZnO}+\mathrm{H}_{2} \mathrm{O}
\end{gathered}
$$

The zinc hydroxide was heat treated for the formation of nanoparticles. The aluminum doped zinc hydroxide was formed by incorporation of $\mathrm{Al}^{3+}$ in the $\mathrm{Zn}^{2+}$ site of zinc oxide lattice using aluminum nitrate nonahydrate as the dopant source material. The incorporation of $\mathrm{Al}^{3+}$ in the $\mathrm{Zn}^{2+}$ site of zinc oxide lattice provides an extra free electron. It is possible to enhance the particle size, morphology and chemical properties of zinc oxide nanoparticles through doping of aluminum in zinc oxide nanoparticles.

\subsection{Characterization}

The X-ray diffraction patterns of nanoparticles were recorded using X-ray diffractometer (BRUKER) with $\mathrm{Cu} \mathrm{K} \alpha$ radiation $(\lambda=1.54060 \AA)$ with a step size of $0.02^{\circ}$. The scanning electron microscope with EDAX (JEOL) was used to examine the surface morphology and to estimate the composition of the prepared samples.

UV-Vis absorption spectra of the nanoparticles were recorded using JASCO, UV-Vis spectrophotometer, USA. The room temperature photoluminescence (PL) spectra of the samples were recorded using a spectrofluorimeter. Fourier transform infrared spectrophotometer SHIMADZU (FT-IR 8400) was used to record FT-IR spectra of the samples.

\section{Results and discussion}

\subsection{XRD analysis}

XRD patterns of nanoparticles prepared by soft chemical method at different conditions are shown in Fig. 1. Analysis of XRD patterns revealed that the prepared samples were crystallized in hexagonal wurtzite structure with a space group $\mathrm{P}_{3} \mathrm{mc}$ (JCPDS card number 897102). All the observed peaks in the patterns matched well with the JCPDS data.

The structural and micro-structural parameters, such as lattice parameters, lattice spacing along with respective reflections and particle sizes were calculated. The lattice parameters were calculated using the equations 4 and 5 .

$$
\begin{gathered}
a=\lambda /\left(3^{\frac{1}{2}} * \sin \theta_{(100)}\right) \\
c=\lambda /\left(\sin \theta_{(002)}\right)
\end{gathered}
$$

where $\lambda$ - wavelength of X-ray and $\theta$ - Bragg angle of the diffraction peak.

The c/a values confirmed that the prepared nanoparticles were crystalline in nature. The calculated values of a and c, tabulated in Table 1, are in a good agreement with reported values $(\mathrm{a}=3.249 \AA$, $\mathrm{c}=5.206 \AA$, JCPDS card number 897102). The calculated values of a and $c$ are lower than the standard values. This lattice shrinkage occurred due to incorporation of $\mathrm{Al}^{3+}$ with the ionic radius of $0.53 \AA$ in place of $\mathrm{Zn}^{2+}$ with the ionic radius of $0.74 \AA$ in the zinc oxide lattice [3].

The unit cell volume for each sample was calculated using the equation 6 .

$$
V=0.866 a^{2} c
$$

From the XRD patterns, Fig. 1, the reflections, namely (100), (002) and (101) were of high intensity, whereas the reflections, such as (102), (110), 

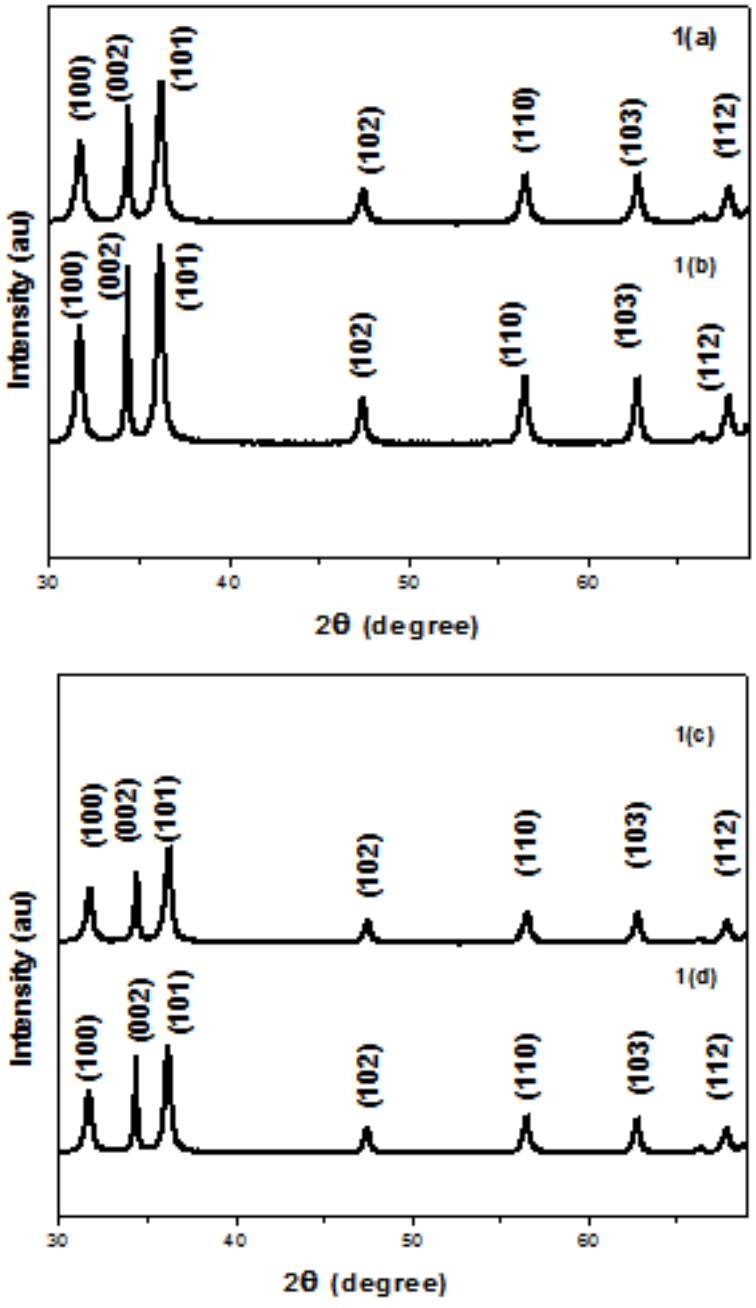

Fig. 1. XRD patterns of zinc oxide nanoparticles: (a) pure, grown at $80{ }^{\circ} \mathrm{C}$, (b) pure, grown at $120^{\circ} \mathrm{C}$, (c) 1 at. $\% \mathrm{Al}$ doped, grown at $120^{\circ} \mathrm{C}$, (d) 3 at. $\%$ Al doped, grown at $120{ }^{\circ} \mathrm{C}$.

(103) and (112), were weak in intensity. The presence of these peaks authenticated the formation of hexagonal wurtzite structure [21]. The reflection (101) was found to have the highest intensity in all the patterns, which indicated that the particles were mostly oriented in the [101] direction [22]. The broad and intense peaks in Fig. 1 confirm the formation of smaller sized zinc oxide nanoparticles $[2,23]$.

The intensity of the strongest peak (101) was reduced in the samples $c$ and $d$ [4]. The diffraction peaks also shifted towards higher angles with the doping of aluminum in zinc oxide lattice of the samples c and d [19]. There was no diffraction peak of aluminum present in the samples $\mathrm{c}$ and $\mathrm{d}$. This was due to the fact that aluminum ions replaced zinc ions and entered into the zinc oxide lattice. The presence of aluminum was confirmed in the samples $\mathrm{c}$ and $\mathrm{d}$.

The particle size of prepared samples was determined by Scherrer equation 7.

$$
D=0.9 \lambda /(\beta \cos \theta)
$$

where $\mathrm{D}$ - the mean crystalline size of particles and $\beta$ - full-width at half-maximum intensity, respectively.

The full-width at half-maximum, $\beta$, was measured with the help of Gaussian fitting program. The calculated particle size of the nanoparticles prepared by soft chemical method was found to vary from $19 \mathrm{~nm}$ to $26 \mathrm{~nm}$ and agreed well with the reported values [13]. All the parameters calculated from XRD data are tabulated in Table 1. It was observed that there was an increase in the values of lattice parameters and particle size with the increase in processing temperature in the soft chemical method [22]. The processing temperature was an important parameter for the formation of high quality nanoparticles.

The interplanar distance of all reflections observed in the individual XRD patterns was calculated using equation 8 and the values are tabulated in Table 2.

$$
d=\lambda /(2 \sin \theta)
$$

where $\mathrm{d}$ - interplanar distance.

The calculated interplanar distances of the reflections for different samples were found to be matched well with each other.

\subsection{SEM and EDAX analysis}

Scanning electron micrographs of the samples a, b, c and d are shown in Fig. 2. The formations of flake-like shaped nanoparticles were observed from these micrographs. The particles were observed to be agglomerated and this type of agglomeration originated from high surface energy of prepared nanoparticles [22]. 
Table 1. The parameters calculated from XRD data.

\begin{tabular}{cccccccc}
\hline Type of sample & Sample & $\mathrm{c}(\AA)$ & $\mathrm{a}(\AA)$ & $\mathrm{c} / \mathrm{a}$ & $\mathrm{V}\left(\AA^{3}\right)$ & $\mathrm{D}(\mathrm{nm})$ in $(101)$ plane & Average D (nm) \\
\hline \hline Standard & JCPDS & 5.206 & 3.249 & 1.602 & 47.590 & - & - \\
Pure & $\mathrm{a}$ & 5.215 & 3.251 & 1.601 & 47.640 & 24 & 26 \\
Pure & $\mathrm{b}$ & 5.206 & 3.257 & 1.601 & 47.907 & 24 & 25 \\
Doped & $\mathrm{c}$ & 5.197 & 3.244 & 1.602 & 47.362 & 19.4 & 20 \\
Doped & $\mathrm{d}$ & 5.195 & 3.243 & 1.602 & 47.314 & 19.2 & 19 \\
\hline
\end{tabular}
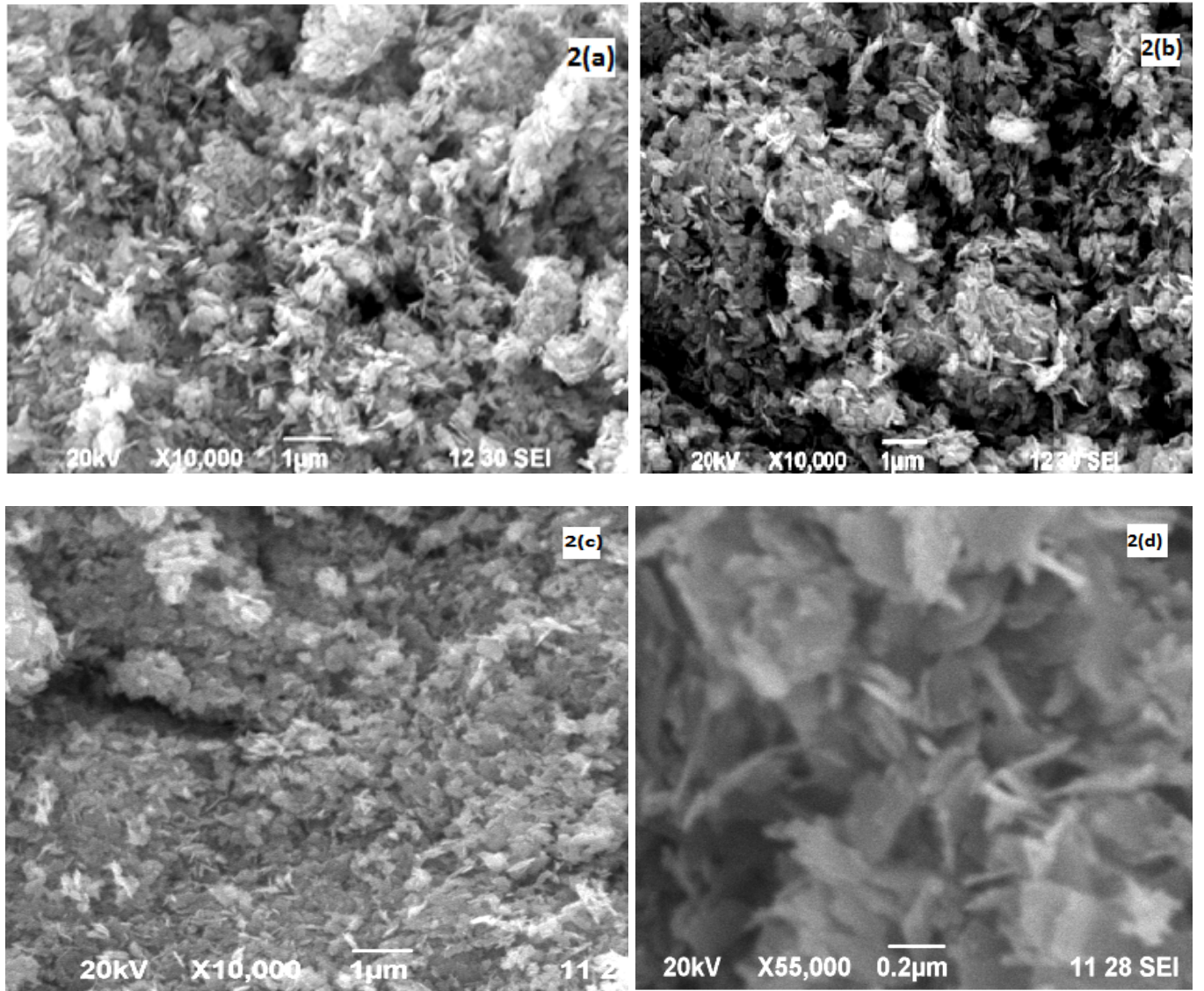

Fig. 2. SEM micrographs of zinc oxide nanoparticles: (a) pure, grown at $80{ }^{\circ} \mathrm{C}$, (b) pure, grown at $120{ }^{\circ} \mathrm{C}$, (c) 1 at.\% $\mathrm{Al}$ doped, grown at $120{ }^{\circ} \mathrm{C}$, (d) 3 at.\% $\mathrm{Al}$ doped, grown at $120{ }^{\circ} \mathrm{C}$.

EDAX spectra of all samples are shown in Fig. 3. Analysis of EDAX spectra revealed that the samples prepared at different conditions had a stoichiometric ratio of constituent elements, zinc, aluminum and oxygen. The spectral analysis of these spectra showed the absence of other elements.

\subsection{UV-Vis spectra analysis}

The absorbance spectra of pure and aluminum doped zinc oxide nanoparticles synthesized at dif- ferent growth conditions are shown in Fig. 4. The absorption peaks present in the individual samples are tabulated in Table 3. The absorption peak values were in close agreement with the reported values [24]. The peak values varied from $351 \mathrm{~nm}$ to $357 \mathrm{~nm}$. The aluminum incorporation was confirmed by the decrease in the peak values. The peak values were found to decrease with decrease in particle size of prepared nanoparticles [25].

The decrease in the band edge was attributed to the change in particle size of the 

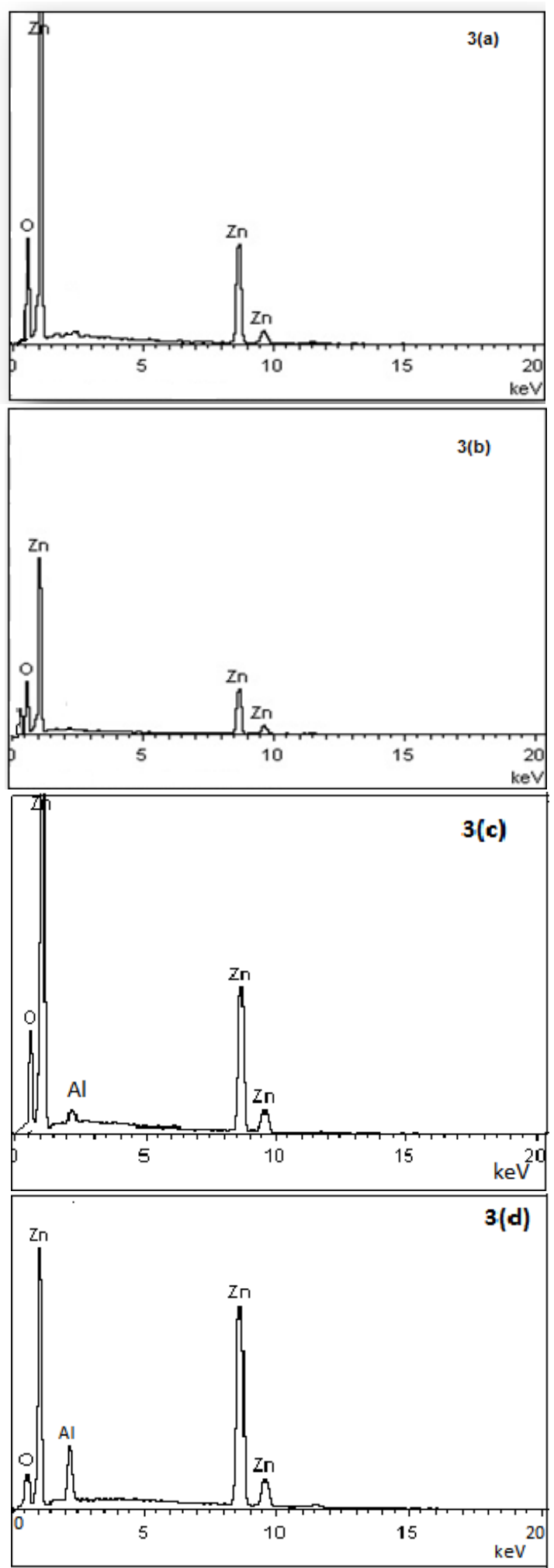

Fig. 3. EDAX spectra of zinc oxide nanoparticles: (a) pure, grown at $80{ }^{\circ} \mathrm{C}$, (b) pure, grown at $120^{\circ} \mathrm{C}$, (c) 1 at. $\% \mathrm{Al}$ doped, grown at $120{ }^{\circ} \mathrm{C}$, (d) 3 at. $\%$ Al doped, grown at $120{ }^{\circ} \mathrm{C}$.
Table 2. Interplanar distance of all reflections observed in the XRD patterns.

\begin{tabular}{ccccc}
\hline \multirow{2}{*}{ Reflection } & \multicolumn{4}{c}{$\mathrm{d}$ spacing $(\AA)$} \\
\cline { 2 - 5 } & $\mathrm{a}$ & $\mathrm{b}$ & $\mathrm{c}$ & $\mathrm{d}$ \\
\hline \hline 100 & 2.819 & 2.817 & 2.813 & 2.803 \\
002 & 2.605 & 2.603 & 2.601 & 2.593 \\
101 & 2.480 & 2.478 & 2.474 & 2.468 \\
102 & 1.913 & 1.912 & 1.910 & 1.907 \\
110 & 1.627 & 1.626 & 1.624 & 1.622 \\
103 & 1.478 & 1.478 & 1.477 & 1.475 \\
112 & 1.379 & 1.379 & 1.378 & 1.377 \\
\hline
\end{tabular}

synthesized nanoparticles. This decrease in particle size originated from the quantum confinement effect [26] and the blue shift observed in the absorbance spectra of nanoparticles was due to the quantum confinement effect [27]. The band gap values of all samples were calculated and listed in Table 3. The band gap was calculated using equation 9 .

$$
E_{g}=(h c) /(\lambda)
$$

where $\mathrm{h}$ - Planck's constant, c - velocity of light and $\lambda-U V-V i s$ absorption wavelength.

The band gap varied from $3.48 \mathrm{eV}$ to $3.53 \mathrm{eV}$. The band gap values were larger than that of bulk and confirmed the formation of small sized particles. As a result of the presence of aluminum, the enhancement of band gap was observed.

Table 3. The parameters measured from UV absorption spectra of the samples.

\begin{tabular}{cccc}
\hline $\begin{array}{c}\text { Type of } \\
\text { sample }\end{array}$ & Sample & $\begin{array}{c}\text { Absorption } \\
\text { wavelength (nm) }\end{array}$ & $\begin{array}{c}\text { Band } \\
\text { gap }(\mathrm{eV})\end{array}$ \\
\hline \hline Pure & $\mathrm{a}$ & 357 & 3.48 \\
Pure & $\mathrm{b}$ & 355 & 3.49 \\
Doped & $\mathrm{c}$ & 354 & 3.50 \\
Doped & $\mathrm{d}$ & 351 & 3.53 \\
\hline
\end{tabular}

\subsection{Photoluminescence spectra analysis}

The room temperature photoluminescence spectra of the synthesized nanoparticles are shown in Fig. 5. The defect related visible emission 

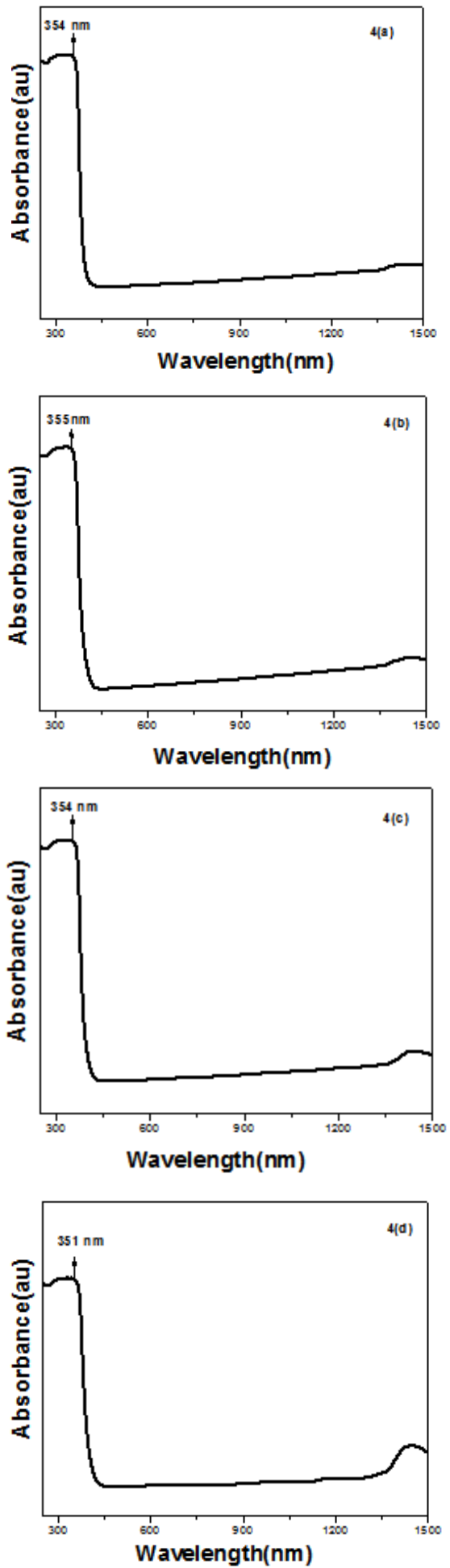

Fig. 4. UV-Vis spectra of zinc oxide nanoparticles: (a) pure, grown at $80{ }^{\circ} \mathrm{C}$, (b) pure, grown at $120^{\circ} \mathrm{C}$, (c) 1 at. $\% \mathrm{Al}$ doped, grown at $120{ }^{\circ} \mathrm{C}$, (d) 3 at. $\%$ Al doped, grown at $120{ }^{\circ} \mathrm{C}$. mechanism was investigated using the room temperature PL spectra of the samples. The different peaks were observed in the PL measurements. The near-band-edge emission of zinc oxide, due to the direct recombination of excitons, was observed at $382 \mathrm{~nm}$ in samples a and b [28]. This recombination confirmed the high surface to volume ratio of the prepared zinc oxide nanoparticles [29].

The green emission peaks were observed at $520 \mathrm{~nm}$ (sample a), $568 \mathrm{~nm}$ (sample b), $508 \mathrm{~nm}$ (sample c) and $492 \mathrm{~nm}$ (sample d). This green emission peaks were found to be connected with the presence of ionized oxygen vacancies [30]. The aluminum incorporation was established with the red emission peaks at $590 \mathrm{~nm}$ and $620 \mathrm{~nm}$ in samples c and sample d [20]. A change occurred in electronic energy levels with the presence of aluminum in zinc oxide nanoparticles. The formation of broad peaks in the PL spectra proved the presence of less intrinsic defects and a good quality of the prepared nanoparticles.

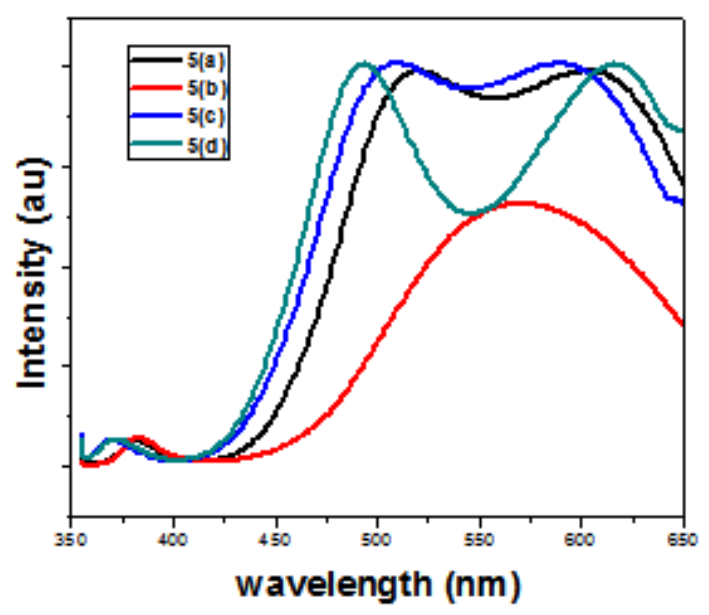

Fig. 5. PL spectra of zinc oxide nanoparticles: (a) pure, grown at $80{ }^{\circ} \mathrm{C}$, (b) pure, grown at $120^{\circ} \mathrm{C}$, (c) 1 at. $\% \mathrm{Al}$ doped, grown at $120^{\circ} \mathrm{C}$, (d) 3 at.\% $\mathrm{Al}$ doped, grown at $120^{\circ} \mathrm{C}$.

\subsection{FT-IR spectra analysis}

The FT-IR spectra of the prepared nanoparticles are shown in Fig. 6. The results of functional group analysis and the FT-IR spectra confirmed the presence of various chemical functional groups and 

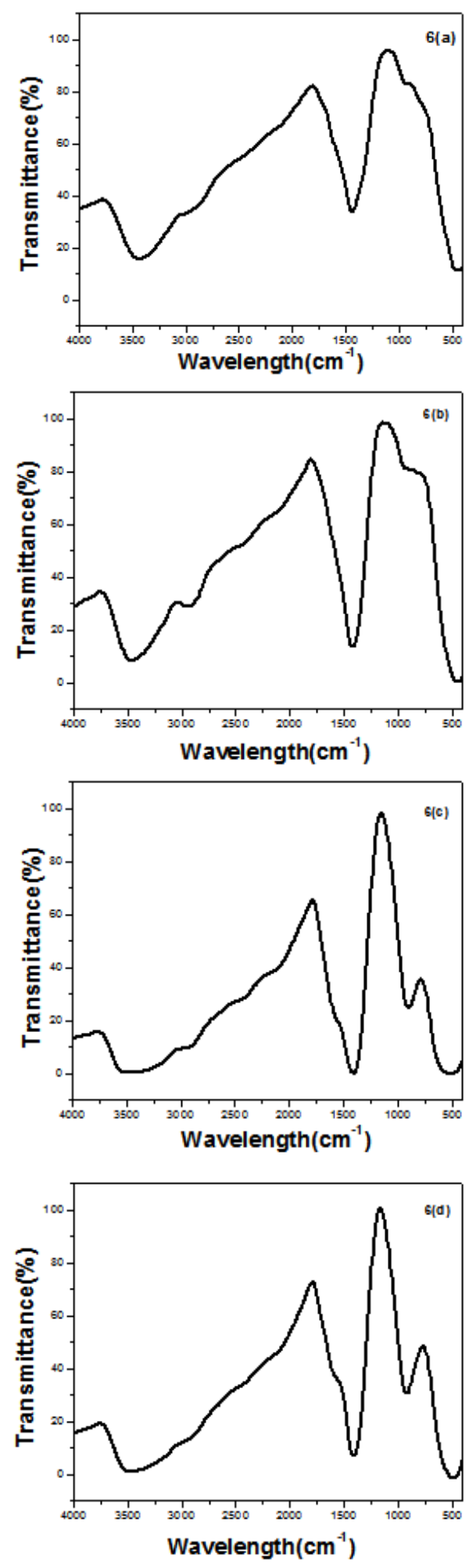

Fig. 6. FT-IR spectra of zinc oxide nanoparticles: (a) pure, grown at $80{ }^{\circ} \mathrm{C}$, (b) pure, grown at $120^{\circ} \mathrm{C}$, (c) 1 at. $\% \mathrm{Al}$ doped, grown at $120{ }^{\circ} \mathrm{C}$, (d) 3 at. $\%$ Al doped, grown at $120{ }^{\circ} \mathrm{C}$. also the formation of pure and aluminum doped nanoparticles. The peaks at $450 \mathrm{~cm}^{-1}, 449 \mathrm{~cm}^{-1}$ in the samples $a$ and $b$, and $500 \mathrm{~cm}^{-1}, 483 \mathrm{~cm}^{-1}$ in the samples $\mathrm{c}$ and $\mathrm{d}$ confirmed the presence of stretching modes of zinc oxide nanoparticles [4]. The $\mathrm{C}=\mathrm{O}$ bands were observed around $1400 \mathrm{~cm}^{-1}$. The absorption peaks around $3400 \mathrm{~cm}^{-1}$ were attributed to $\mathrm{O}-\mathrm{H}$ stretching. The aluminum incorporation was confirmed by the presence of peaks at $890 \mathrm{~cm}^{-1}$ and $920 \mathrm{~cm}^{-1}$ in the samples $\mathrm{c}$ and $\mathrm{d}$.

\section{Conclusions}

In conclusion, pure and aluminum doped zinc oxide nanoparticles were successfully prepared by soft chemical method. XRD studies indicated that the prepared nanoparticles had hexagonal wurtzite structure with good crystallinity. A shrinkage of the lattice was observed with the incorporation of aluminum in zinc oxide nanoparticles. The reflection (101) was found to have the highest intensity in all the patterns, which indicated that the particles were mostly oriented in the [101] direction. The estimated average particle size was $19 \mathrm{~nm}$ to $26 \mathrm{~nm}$. The c/a values confirmed the good crystallinity of the samples. The SEM micrographs showed an agglomeration of the nanoparticles over the surface. The presence of elements zinc, aluminum and oxygen was confirmed by EDAX analysis. The UV-Vis absorption peak values varied from $351 \mathrm{~nm}$ to $357 \mathrm{~nm}$. The enhancement of band gap was observed due to incorporation of aluminum in the zinc oxide nanoparticles. The chemical functional groups in FT-IR spectra proved the formation of zinc oxide nanoparticles. The nearband-edge was found around $380 \mathrm{~nm}$ in PL measurements. There was a change in electronic energy levels in presence of aluminum in zinc oxide nanoparticles. Thus, these results showed the formation of good quality pure and aluminum doped zinc oxide nanoparticles.

\section{References}

[1] Ozgur U., Alivov Ya.I., LiU C., Teke A., Reshchikov M.A., Dogan S., Avrutin V., Cho S.J., MorkoC H., J. Appl. Phys., 98 (2005), 041301.

[2] Kalandaragh Y., Khodayari A., Behboudnia M., Mat. Sci. Semicon. Proc., 12 (2009), 142. 
[3] Shui A., Wang S., Wang H., Cheng X., J. Ceram. Soc. Jpn., 117 (2009), 703.

[4] Saravanakumar K., Ravichandran K., J. Mater. Sci.-Mater. El., 23 (2012), 1462.

[5] Khan W., Khan Z. A., SaAd A., Shervani S., SAlEem., NAQVi H., Int. J. Mod. Phys., 22 (2013), 630.

[6] Viswanatha R., Arthoba Nayak Y., VenkateSHA T.G., VIDYASAGAR C., Nanosci. Nanotech.-Int. J., 3 ( 2013), 16.

[7] Ullah R., Dutta J., J. Hazard. Mater., 156 (2008), 194.

[8] Kant S., Kumar A., Adv. Mat. Lett., 3 (2012), 350.

[9] Udayakumar S., Renuka V., Kavitha K., $J$. Chem. Pharm. Res., 4 (2012), 1271.

[10] Milenova K., Stambolova I., Blaskov V., Eliyas A., Vassilev S., ShipochKa M., J. Chem. Technol. Metall., 48, 3(2013), 259.

[11] LeE T., Sue H., Cheng X., Nanoscale Res. Lett., 6 (2011), 1.

[12] Dhingraa M., Singha N. K., Shrivastavab S., Senthil Kumar P., Annapoorni S., Sensor. Actuat. A-Phys., 190 (2013), 168.

[13] Arefi M., Zarchi S., Imani S., Afr. J. Biotechnol., 11 (2012), 8520.

[14] Renganathan B., Sastikumar D., Gobi G., RaJeswari Yogamalar N., Chandra Bose A., Sensor. Actuat. B-Chem., 156 (2011), 263.

[15] Navale S.C., Ravia V., Mulla I.S., Gosavi S.W., Kulkarni S.K., Sensor. Actuat. B-Chem., 126 (2007), 382.

[16] Dwivedia C., Dutta V., AIP Adv., 3 (2013), 32127.

[17] Piticescu R.R., Piticescu R.M., Monty C.J., J. Eur. Ceram. Soc., 26 (2006), 2979.
[18] Chen K.J., FAng T.H., Hung F.Y., Ji L.W., Chang S.J., Young S.J., Hsiao Y.J., Appl. Surf. Sci., 254 (2008), 5791.

[19] Zhang Y., YAng Y., ZhaO J., TAN R., WANG W., Cui P., Song W., J. Mater. Sci., 46 (2011), 774.

[20] Kadam P., Agashe C., Mahamuni S., J. Appl. Phys., 104 (2008), 103501.

[21] Kong J., Fan D., Zhu Y., Mat. Sci. Semicon. Proc.,15 (2012), 258.

[22] RaOufi D., Renew. Energ., 50 (2013), 932.

[23] Wahab R., Hwang I., Kim Y., Musarrat J., SidDiqui M., KeE SEd H., TRipathy S., Shin H., Chem. Eng. J., 175 (2011), 450.

[24] Singh D.K., Pandey D.K., Yadav R.R., Singh D., Pramana-J. Phys., 78 (2012), 759.

[25] Samuel S., Bose L., George., SB Acad. Rev., 16 (2009), 57.

[26] Khan Z.R., Arif M., Singh A., Int. Nano Lett., 2 (2012), 1.

[27] Zandi S., Kameli P., Salamati H., Ahmadvand H., HaKimi M., Physica B, 406 (2011), 3215.

[28] Grabowska J., Nanda K.K., Mcglynn E., Mosnier J.P., Henry M.O., BEAUCAMP A., MeAney A., J. Mater. Sci.-Mater. El., 16 (2005), 397.

[29] Peng W.Q., Qu S.C., Cong G.W., Wang Z.G., Mat. Sci. Semicon. Proc., 9 (2006), 156.

[30] Wang R., Tsai C., Appl. Phys. A-Mater., 94 (2009), 241.

Received 2014-02-19 Accepted 2014-11-19 